DOI:10.1145/1467247.1467248

\title{
"Yes, It Can Be Done"
}

The 2008 presidential campaign slogan "Yes, We Can" is the English translation of the United Farm Workers' 1972 slogan "Sí, se puede," or "Yes, it can be done."

In 2005, I had a conversation with a member of ACM's Publications Board about the (then nascent) idea of revitalizing Communications. I was very pessimistic then, saying, "It cannot be done." About a year later, in the fall of 2006, I undertook that very task. Now, it is March of 2009, and we can say, "Yes, it can be done."

Why was I wrong in 2005? To start, I underestimated the determination of ACM's leadership to turn Communications around. I also underestimated the willingness of Communications' staff to undertake a radical change in the way they go about their jobs. Most of all, I underestimated ACM membership's intense desire for change and willingness to volunteer their effort toward the development of a flagship publication of which we can all be proud.

In my January 2008 editorial, I described Communications' editorial model as we envisioned it. Since I view this publication as a joint project between our Editorial Board and ACM's membership, it is important, I believe, that our editorial model be well understood. In January, I explained how our News and Viewpoints boards operate.

Our Practice Board, chaired by Stephen Bourne, with James Maurer as publisher, has a dual personality. On one hand, it is part of Communications' Editorial Board, with responsibility for developing the content for the Practice section. On the other hand, that same board is also Queue's Editorial Board, with the closely re- lated, but independent, task of developing practitioner content for ACM, primarily through the Queue Portal, at queue.acm.org. This board thrives on intense face-to-face interaction, meeting monthly to discuss emerging technologies. They identify topics of current interest to software architects, project leaders, IT managers, and corporate decision makers. The board also identifies potential authors and then commissions them to develop articles, under the guidance of board members and invited guest experts.

The Contributed Articles Board, chaired by Al Aho and Georg Gottlob, operates like a traditional editorial board of a scientific journal. Unsolicited manuscripts are submitted via Manuscript Central, a Web-based system for facilitating a fully online review process. As this board handles both Contributed and Review articles, the co-chairs assign each submission to an associate editor, who oversees a scholarly review process. The cochairs and associate editors can decide to decline a paper without further review, if they judge it does not fit our new content model.

The bar for acceptance is very high; articles must be of the highest quality and reach out to a very broad technical audience. A significant fraction of the submissions fit Communications' previous editorial model and must be declined. A major task of this board is to encourage submissions by authors inspired by the new editorial model. It is fair to say that attracting
Moshe Y. Vardi

high-quality Contributed and Review articles is an ongoing effort.

The Research Highlights Board aims to leverage the unique feature of computing research from our highly selective conferences. Their goal is to provide readers with a collection of outstanding research articles, selected from the broad spectrum of computing-research conferences, and reposition them for a far more diversified audience. Submissions are first nominated by Board Members or Approved Nominating Organizations and are subject to final selection by the Board. Authors are invited to rewrite and expand the scope of their research papers to address Communications' broad readership.

Each of these articles is accompanied by a Technical Perspective essay, providing readers with a one-page overview of the underlying motivation and important ideas of the featured research as well as its scientific and practical significance. Technical Perspective essays are written by rising stars and established luminaries invited by the Board. The challenge for this Board is to develop a reach into hundreds of computing-research conferences. So far, only about 10 ACM SIGs have applied to become Approved Nominating Organizations. We hope to see more SIGs applying this year, as well as non-ACM organizations.

This, in a nutshell, is how Communications' editorial work is carried out. I've also tried to give you a sense of the ongoing challenges. Producing a top-notch flagship publication is an evolving project. I am pleased with the progress we have made so far, and am acutely aware of the efforts required to sustain and improve upon the quality of this magazine. Yes, it can be done, if we, ACM members, collectively shoulder this effort.

Moshe Y. Vardi, EDITOR-IN-CHIEF 